\title{
INTERVIEW
}

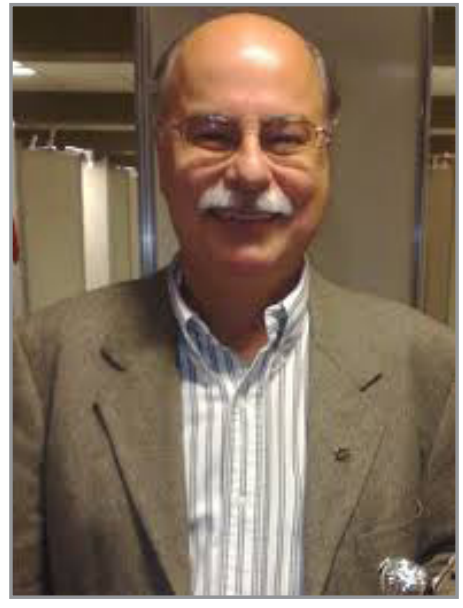

\section{Prof. Santelli, a Tireless Researcher and a Gold-Standard Professor in Analytical Chemistry, kindly spoke to BrJAC}

\author{
Ricardo Erthal Santelli $\mathbb{B}$ ه \\ Full Professor \\ Federal University of Rio de Janeiro, RJ, Brazil
}

Prof. Dr. Ricardo Erthal Santelli has a degree in Pharmacy from the Federal Fluminense University, Niterói, RJ, BR (1972), a master's degree in Inorganic Analytical Chemistry from the Pontifical Catholic University, Rio de Janeiro, RJ, BR (1978), a doctorate in Inorganic Analytical Chemistry from the same institution (1985), and a postdoctoral degree from the University of Córdoba, Spain (1988). He was a full professor of Environmental Geochemistry at the Federal Fluminense University from 1994 until 2010 when he retired.

He is currently Full Professor at the Institute of Chemistry at the Federal University of Rio de Janeiro, BR. He works mainly with the development of spectrometric and chromatographic methods, continuous flow injection analysis, and speciation analysis. He develops research mainly on automation in analytical chemistry, environmental geochemistry, and analytical techniques applied to environmental problems.

Prof. Santelli has more than 140 scientific articles published in international journals, with more than 5800 citations and an $\mathrm{H}$-index of 32 in addition to several chapters in international books. He has supervised more than $\mathbf{3 0}$ master's and 15 doctoral students. In the editorial field, Prof. Santelli is currently a member of the Editorial Board of the Brazilian Journal of Analytical Chemistry.

What early influences encouraged you to study science? Did you have any influencers, such as a teacher?

Since I was a child/teenager, I was very curious about scientific discoveries both in the exact sciences and in the medical field. Also, I liked astronomy (I used to buy the newspaper to read a weekly column about astronomy) and electronics (I used to attend technical courses on electronics by correspondence and also in person). However, my passion at that time was for a children's game called "The Little Chemist". I had a lot of fun performing the experiments described in the game as well as inventing new ones with the available reagents. At the time I attended secondary school, it was not common for schools to have science laboratories, especially in cities in the interior of Rio de Janeiro state, such as Nova Friburgo, where I lived. Only a few high standard schools had laboratories, and I was very eager to visit them, but this was not an easy task. 
Later, already in the last year of high school and preparing to take the university entrance exam, I met Prof. Per Christian Braathen who taught chemistry. In that year (1969), Prof. Per was finishing his Chemistry degree at the State University of Rio de Janeiro (UERJ) and had been hired by the prestigious "Colégio Nova Friburgo", at the time managed by the Getúlio Vargas Foundation, which also taught night classes at the "Colégio Modelo" where I was a student. As I was very interested in Chemistry, I soon became friends with Prof. Per. From this friendship came an invitation to visit the laboratories at "Colégio Nova Friburgo" on a Saturday afternoon. After this first visit, many Saturday afternoons were pleasantly spent in the laboratory, performing the most varied chemistry experiments (and after the practices, we always had a snack carefully prepared by Prof. Per's wife).

Later on, Prof. Per and I were colleagues in the postgraduate course and also professors at the Department of Chemistry at the Pontifical Catholic University, Rio de Janeiro (PUC/Rio) and later professors at the Institute of Chemistry at the Federal Fluminense University (UFF). Therefore, although I already liked Chemistry, Prof. Per proved to be fundamental for my future choices.

\section{When did you decide to study chemistry? What motivated you? How was the beginning of your career?}

On the occasion of the university entrance exam, I was thinking of applying for a place in the medical course. I was fascinated by the first heart transplant performed in South Africa by Prof. Christian Barnard. So, I thought about becoming a cardiologist. But, despite loving medicine, I didn't like the hospital environment and much less the sight of blood. Thus, that choice became impossible. Guided by a cousin who was a veterinarian, I decided to take the entrance exam for the Pharmacy course. In a way, there was something about medicine and also about chemistry in the pharmacy course. I passed the entrance exam and started studying Pharmacy at UFF in 1970.

Right in the second semester of the pharmacy course, I was a monitor in organic chemistry. In 1971, UFF created a postgraduate course (master's) in Geochemistry, and I was invited to be the laboratory assistant for this course. This invitation was made by the late Prof. Luiz Fernando Aguiar de Carvalho, who had made his career at the National Department of Mineral Production (currently, Geological Survey of Brazil - CPRM) and had recently been transferred to UFF, where he specialized in emission spectrography with the eminent Prof. Paulo Emídio Ferreira Barbosa.

UFF had received, among other equipment, an emission spectrograph with arc and spark source from the German manufacturer Aus Zena (from the former East Germany). This equipment had been exchanged by the Brazilian government for coffee. I was in charge of operating the emission spectrograph and performing most of the analyses for the first students in the geochemistry course. This was my first real apprenticeship in analytical chemistry. I prepared the samples (usually ores such as cassiterite) either by acid treatment or by fusion with fluxes such as sodium peroxide. Separation and preconcentration techniques such as sorption on silica and solvent extraction were common. The work was hard, but the learning was fantastic. After sample preparation, quantification was done. Those who are more experienced with atomic spectrometry know that at that time, the detector used was a special photographic emulsion (photographic film) (with sensitivity also for the ultraviolet region) that had to be handled in the dark. Before constructing the calibration curve, the photographic emulsion had to be calibrated. It took us days to do this because it involved a lot of calculations, and we had no calculator and even less computers. I ended up becoming a spectroscopist.

I did all this in parallel with the Pharmacy course until my graduation in 1972. In early 1973 , I was invited by the then Director of the Institute of Chemistry at UFF, Prof. José Chianelli, to conduct a Chemistry course for students in the geography course, and soon afterwards, I took an internal selection exam (at that time, there were no public tenders as there are today) for assistant professor of experimental analytical chemistry. It was the beginning of my teaching career in analytical chemistry, which has lasted until today. 


\section{What has changed in the student profiles, ambitions, and performance since the beginning of your career?}

I think everything changes a little over time. Initially, as a student, there is a huge concern to learn and pass the subjects of the university course. Personally, I managed to finish my degree in regular time, and I can say that I was a standard student. In fact, I lived to study.

In professional life, one wishes to have a more solid knowledge of science and particularly of the discipline one has chosen to follow. This requires much more study, effort, dedication, and continuous work when compared to the student. The ambitions are also different. As a student, we want to finish the course and get a good job right away, which is quite difficult nowadays. The student's ambitions are short term. In academic life, we envision success and recognition in the future, but this involves everything I mentioned before. Teaching and scientific research require full dedication, sometimes even hindering one's social life.

\section{Could you briefly comment on recent developments in inorganic analytical chemistry, considering your contributions?}

Inorganic analytical chemistry as a whole, worldwide and particularly in Brazil, has evolved a lot in the last decades. This evolution was (and will always be) fundamental for the scientific and technological development of humanity. For the development of new strategic materials and better use of their characteristics, their characterization and production control are necessary. Typically, these materials must have extreme purity, such as the silicon used in the manufacture of semiconductors, or have a well-defined

"I believe that the best thing I have done (and still do) in these almost 48 years of teaching is to guide students of analytical chemistry to dedicate themselves to their studies because I believe that this is the only way to form competent professionals." composition, such as catalysts. The characterization and production control of new strategic materials are some of the activities of today's inorganic analytical chemistry, and without the development of these activities, it is impossible to aim for an improvement in our quality of life, in the environmental protection, and improvement of practically everything around us.

In the field of human nutrition, the characterization and quantification of inorganic species (such as metals) in human milk and infant formula is fundamental for the nutrition of newborns. In the field of medicine, it is also essential to correctly diagnose several illnesses, such as Parkinson's disease and Wilson's disease.

Nowadays, it is common for an inorganic analytical chemist to handle a "medical" periodic table. Elements that were relatively unknown until recently, such as gadolinium, which is present in contrast agents for magnetic resonance exams, are now being studied in inorganic analytical chemistry laboratories. The interest in gadolinium, in particular, can be explained because its action in the human body, especially in the brain, is still little known and because of its dispersion in water bodies causing an environmental impact.

Regarding my contributions, I believe that the best thing I have done (and still do) in these almost 48 years of teaching is to guide students of analytical chemistry to dedicate themselves to their studies because I believe that this is the only way to form competent professionals. I have also tried to guide students to the correct use of scientific nomenclature in analytical chemistry. Unfortunately, there are some books that insist on not caring about scientific rigor. And so, the students learn wrongly and the mistakes multiply over time.

\section{What are your lines of research? You have published many scientific papers. Would you highlight any?}

When I finished my doctorate in inorganic analytical chemistry, I spent some time looking for a research line to start working autonomously. At that time, flow injection analysis (FIA) was under great development in the world, particularly in Brazil, especially with the group of the Center of Nuclear Energy in Agriculture of the University of São Paulo (CENA/USP). I made several contacts with Professors Elias A. G. Zagatto 
and Antônio O. Jachinto. I received many teachings from them and started to work with FIA. At that time, everything was still very handmade. It was necessary to build switches to insert the solutions in the continuous system and in the flow cuvettes in addition to improvising a lot. But it worked very well. As I was working in a geochemistry department at UFF, I automated almost all determinations of major elements and some minor elements in rocks by FIA.

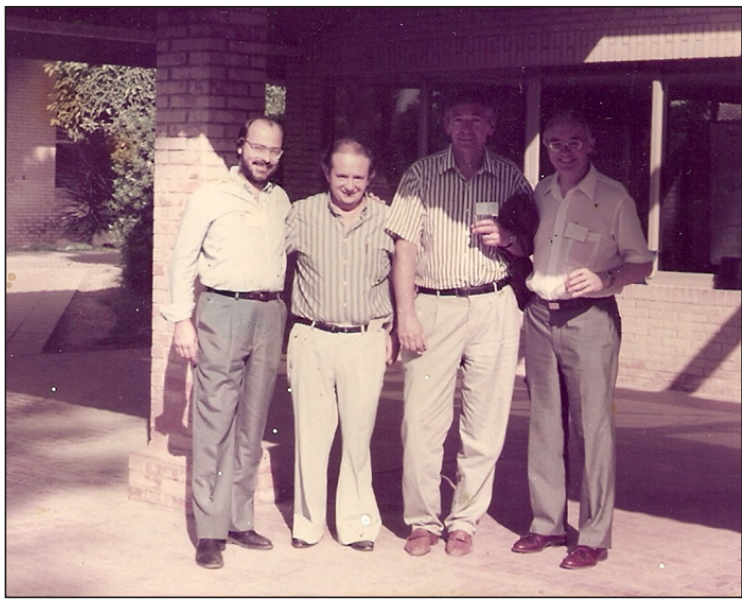

Ricardo Santelli, Miguel Valcárcel, Jarda Ruzicka and Gary Christian at Universidad de Córdoba, 1992.
Afterwards, I did a post-doctoral period at the Universidad de Córdoba in Spain under the supervision of Prof. Miguel Valcárcel (one of the eminent researchers from Spain and the European Community). I learned a lot from him and from Prof. Mercedes Gallego. I could also see how creative we Brazilians are and how productive we can be abroad with a better laboratory structure. There, I published my first article in the Analytical Chemistry journal. Coming back from postdoc, I was able to form a group with many undergraduate students and publish some papers in good journals with several partners from other universities.

As I spent many years in a geochemistry department, whose main interests were environmental issues, I published (and still publish) many works with several colleagues in the area, mainly on the quality of water, soils,

and sediments. Also, from that time onwards, I became interested in Atomic Spectrometry, and I have been working a lot with Atomic Absorption Spectroscopy (high resolution), ICP OES, and more recently with ICP-MS. Currently, I am more interested in the application of atomic spectrometry and chemical speciation analysis to understand the action and metabolism of some important inorganic elements in the fields of human nutrition and medicine.

Do you keep yourself informed about the progress of research in chemistry? What is your opinion about the current progress of chemistry research in Brazil? What are the recent advances and challenges in scientific research in Brazil?

I try to keep myself well informed about scientific developments in chemistry and particularly in analytical chemistry. However, I confess that being well informed about recent innovations in analytical chemistry is not an easy task, indeed it is almost impossible. The huge number of papers and information released each day is unbelievable. However, it is necessary to stay alert. Today, there is an industry of scientific production with the appearance of many scientific journals that do not have good quality criteria. I say industry because the publisher of a scientific journal invests little and seeks profit. The authors write the papers, the reviewers comment and suggest changes, the authors adjust their paper, in many cases pay for the publication, and finally the publisher puts it in the final format and sells access to the articles. It is not difficult to see that the profit can be large. One must always pay close attention to scientific quality.

Brazilian chemistry and, in particular, Brazilian analytical chemistry are quite vigorous on the world scene. Over the last few decades, many scientific research groups have been consolidated in Brazil, generally allied to postgraduate courses that were designed to train human resources of great academic and scientific quality. These groups are many, and it is not possible to name them here.

Our challenges are tremendous, and the main one would be to make this unequal country much more egalitarian. I think we need to look for more and more scientific and technological solutions that are genuine and developed by us Brazilians, without leaving aside everything that is good even if imported, in order to advance rapidly in strategic areas, such as engineering, so as to guarantee the full development of our country. However, for some years now, funding for scientific and technological research as well as the training of qualified personnel have been falling sharply in Brazil. Without funding, there is no education, science, and technology, the pillars of a nation. Today, few researchers are able to carry out quality scientific and technological research in Brazil among the many qualified researchers that exist. Our country needs 
to immediately reverse this situation of low funding; otherwise, research will become irreversibly unfeasible in the not-too-distant future.

\section{For you, what have been the most important recent achievements in analytical chemistry research? What are the landmarks?}

In modern analytical chemistry, we cannot do without equipment. I think the great recent advance in analytical chemistry has been the development, modernization, and improvement of scientific instrumentation. Of course, this is due to the great development of two other related areas, electronics and computer science. In inorganic analytical chemistry, the advent of mass spectrometers that are increasingly sensitive, precise, accurate, and with the most diverse accessories allow the elucidation of questions, mechanisms, total quantification, and speciation of various chemical elements of fundamental importance in the modern world. The possibility of monitoring isotopes, whether in a living organism, in the environment, or in any material, gives us answers to several important questions, such as, for example, in toxicology. Today, we want to live longer and better, and for this, the understanding of the toxicology of a chemical element is fundamental.

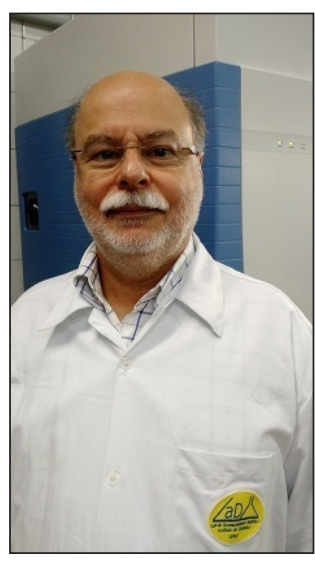

Prof. Santelli at the Analytical Development Lab, Federal University of Rio de Janeiro

There are in Brazil, and in the world, several conferences on Chemistry. To you, how important are these meetings to the chemistry scientific community? How do you see the development of national chemistry meetings in Brazil?

Scientific events are fundamental for the dissemination of knowledge and exchange of information with peers. In addition, they are inexhaustible sources of knowledge for new students and researchers. Science is learned in many ways, and one of them is by attending congresses. This activity must be increasingly encouraged, although sometimes, it seems that there are already too many congresses. It is necessary to understand that the scientific community is also growing, hence the need for more events. In Brazil, I have seen this activity growing and with good participation from young students. This has been happening for some decades in our country, and I would dare to say that this activity was very important for the growth of Brazilian analytical chemistry. Unfortunately, the COVID-19 pandemic and more recent financial issues concern the Brazilian scientific community. A remote conference is quite different from a face-to-face one. The collective exchange of information and the conversation with a more experienced researcher are fundamental for a young researcher. I hope that soon the pandemic will slow down and that the financial conditions of our country will allow the return of face-to-face events and the participation of younger people.

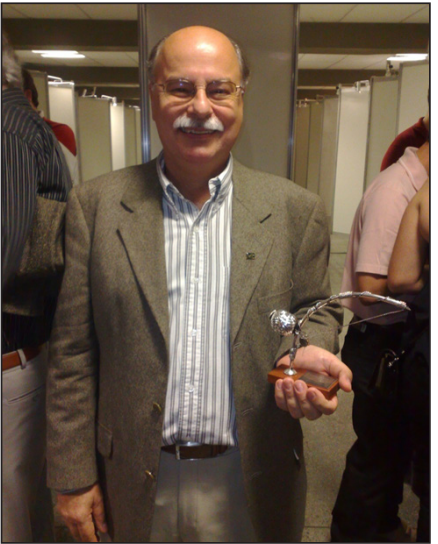

Prof. Santelli with his award received at ENQA 2009.
You have already received some awards. What is it like to receive this kind of recognition?

Receiving recognition and being awarded is always good for everyone, but for those who work in science, it is very rewarding. Being recognized brings us joy, pride, and a sense of accomplishment. Of the awards I have received, especially for two of them, I have immense affection and pride. One was the recognition received on the occasion of the $1^{\text {st }}$ National Meeting of Chemical Speciation - EspeQBrasil in São Pedro, SP in 2008, and the other occurred during the $15^{\text {th }}$ National Meeting of Analytical Chemistry - ENQA in Salvador, BA in 2009. However, I believe that the greatest recognition comes from the students at all levels of education, from undergraduate through scientific initiation, master's and doctoral degrees to postdoctoral studies. I have been 
Prof. Santelli, a Tireless Researcher and a Gold-Standard Professor in Analytical Chemistry, kindly spoke to BrJAC

fortunate to work with and become friends with countless students to whom I have always tried to pass on lessons of ethics and honesty as well as the encouragement and need for serious work to build a solid career not only in academic but also professional life.

What is the importance of these awards in the development of science and new technologies?

Recognition stimulates our creativity and desire to move forward. In fact, there are awards more focused on the development of new technologies, which are generally supported by Companies, which stimulate science as a whole. But I consider that a scientist should not worry about awards and recognition. This is a natural consequence of their activity and their production carried out in an exemplary manner.

\section{For you, what is the importance of the national funding agencies for the scientific development of Brazil?}

I believe that the support of these agencies, whether federal, state, or private, is fundamental for the scientific and technological development of our country. Unfortunately, as mentioned before, our leaders do not have this vision. What we are witnessing is a drastic and gradual reduction in the promotion of research and human resources training (scholarships). This will certainly hinder the country's growth and the construction of a fairer nation in which people can have the education, food, and comfort that every citizen deserves.

Right now, we are facing a radical change in the allocation of master's and doctorate scholarships and in postgraduate courses by the Coordination for the Improvement of Higher Education Personnel (CAPES). I have never been in favor of an excessive distribution of scholarships, but in a continental country like Brazil with countless universities, opportunities must be maintained. However, I assume that the distribution of scholarships should be made considering mainly the merit of the student.

The private sector also has a great responsibility in promoting scientific research in the country. Every company has a social role, and one way to exercise it would be to offer a fraction of its profits for the training of human resources and for scientific and technological research. This is still incipient in Brazil, but I believe that with a good federal government, which is really concerned with the development of our country, such initiatives can be increased and consolidated in the medium term.

"Studying means much more than reading a book or a scientific article. Studying means spending hours on topics of interest and checking all its possibilities, consulting books and related scientific articles."
At the moment, the situation for scientific research in Brazil is one of decreasing investment. How do you see this situation, and what would you say to young researchers?

What I can say to the young researchers is to have hope and perseverance. Take advantage of all the opportunities that are offered and study hard. If you are very well prepared, with broad, strong, and consolidated knowledge, it will be easier to be in a good job and overcome times of crisis like the one we are experiencing at the moment. Knowledge we have to acquire on our own, so it takes a lot of study and dedication. Nowadays, with the quality and quantity of information that we can access, we only depend on ourselves to be prepared and to face the needs and requirements of today's world. Studying means much more than reading a book or a scientific article. Studying means spending hours on topics of interest and checking all its possibilities, consulting books and related scientific articles. It also means listening to the experts, their stories, positions, and interpretations of scientific phenomena.

\section{What advice would you give to a young scientist who wants to pursue a career in inorganic analytical chemistry? \\ I think this answer has already been given before. Studying is the correct and fundamental action. In the specific case of Inorganic Analytical Chemistry, start studying from "old" books to understand and assimilate the essence of analytical chemistry. The fundamental principles of analytical chemistry do not change and,}


therefore, need to be absorbed correctly. Also, nomenclature and scientific rigor must be cultivated. The "Classical Analytical Chemistry", although little used experimentally today, brings us the whole basis and essence of Analytical Chemistry. From this classical knowledge, we then have the possibility to advance in relation to modern analytical techniques, generally instrumental. It is necessary to know the fundamental principles of the techniques, of the instrumentation, and also of how chemical analysis can be carried out reliably. Reliability is fundamental in Analytical Chemistry. A chemical analysis is only valuable if it is performed following a series of analytical quality parameters. I don't think I need to mention that equipment is not magic. Any sample submitted to an instrumental measurement will present a result. But this result must be valid, reliable, and must be validated according to adequate statistical parameters.

I don't know if I will be redundant, but it is worth remembering that it is from the result of a chemical analysis that the decision will be made. Imagine the damage if the result of an analysis is unreliable. Completely wrong decisions will be made.

\section{How would you like to be remembered?}

I honestly don't pretend to be remembered. I have always tried to carry out my teaching, research, and management activities with love, dedication, balance, fairness, and honesty. I don't know if I have behaved this way over the years, but that was my intention. I think that for all that I have done in these 48 years of university life, I will leave a small legacy, probably for a few.

In fact, I think it is more important to recognize people's accomplishments while they are active, that is, while they are alive. I would like to think that I have contributed a little and in a possible way to present inorganic analytical chemistry as very important in chemistry courses at all levels.

I want to remember here another professor who inspired me a lot, the late Prof. Dr. Adilson José Curtius, to whom I owe all my master's and doctorate education and my passion for atomic spectrometry.

So, to close this interview, I would really like to be remembered as a professor who helped (or at least tried to help) many students in the field of Chemistry. 